\title{
Exploring the Challenges Encountered by Students of Higher Education in Saudi Arabia Employing Hybrid MOOCs
}

\author{
Homoud Alanazi ${ }^{1,2}$, Caroline Walker-Gleaves ${ }^{1}$ \\ Newcastle University1, United Kingdom \\ Taif University2, Saudi Arabia
}

\begin{abstract}
Challenges confronting students' learning via Massive Open Online Courses (MOOCs) as intrinsic parts of Flipped Classrooms within Saudi Arabian higher education is an untouched area of enquiry within education research. The literature has shown that certain scholars have begun to explore this area, but so far for other countries only, scrutinising difficulties and obstacles when this new teaching method has been implemented. This paper aims to identify the challenges that exist for $1^{\text {st }}$ year undergraduate students studying at the Education Faculty of Majmaah University in Saudi Arabia in the $1^{\text {st }}$ academic semester of 2017/2018, during a 14-week period, to teach the students of the 'Educational Technology and Communications Skills' module by using Hybrid MOOCs with Flipped Classrooms pedagogy. It employs a mixed methods approach, including questionnaires (quantitative approach) together with semi-structured interviews (qualitative approach). The results of this research reveal that students encountered challenges regarding the platform (Rwaq), but mostly not directly related to MOOCs or their affordances, and instead, more related to internet quality. Regarding the Flipped Classrooms, at the beginning students faced some challenges which were more socially orientated rather than directly linked with the use of MOOCs with Flipped Classrooms. Furthermore, most students appeared to overcome their challenges with the aid of the platform support team and their teachers which highlights the importance of human assistance, even in a technology enhanced teaching and learning methods. This paper highlights a possible new avenue for the future of Saudi Arabian education and contributes original research to fill a conspicuous gap in the education literature of the country. Finally, the paper's implications can be seen relevant, not only for Saudi Arabia, but for the rest of the Arabian Gulf countries as they have similar cultural, educational, and economic frameworks.
\end{abstract}

\section{Introduction}

In recent years, Massive Open Online Courses (MOOCs) have become an important new learning method, especially since they were launched by faculty members at the University of Manitoba in 2008. They present a new method of teaching which has attracted the interest of a large number of universities and schools around the world who have integrated or adopted MOOCs in their curriculum. There are several potential reasons behind this. First, MOOCs can be applied in all levels of education and with different motivations and emphases. They can be applied to higher education, in addition to being implemented for primary and secondary schools. Second, MOOCs help to overcome several issues of access to education, and support people to complete their education for lifelong learning in school, university, and distance learning [1]. They give people the ability and freedom to learn what they want, any time or place, and are open for anyone to use. Third, they offer learners a great opportunity to study courses offered by specialists from world class universities such as Massachusetts Institute of Technology (MIT) and Harvard University, usually free of charge, as well as granting certificates to them.

On the other hand, there are several criticisms within literature that point to the limitations of using MOOCs, especially in Higher Education. The first criticism refers to the high dropout rate of students who do not complete their courses. One notable case is the course, 'Circuits and Electronics 6,002x', which was launched in two platforms, MITx and edX, in 2012. The number of participants who registered on MITx were 154763, while 46000 enrolments occurred in the edX platform. However, the number of participants who completed the course in the MITx and edX platforms were $7157(4.6 \%)$ and 3008 (6.5\%), respectively. Many reasons have been suggested for this level of dropout, such as no real intention to complete, lack of clear salience of material, course difficulties, lack of support, lack of digital skills or learning skills, and bad educational experience [2].

Other criticisms have also been voiced against the use of MOOCs for education, such as time spent for preparing all online course materials. One instance is when 9 instructors participated in developing and delivering 10 courses at the University System of Maryland (USM) during one semester. Faculty members documented the time spent on planning, watching all the MOOCs videos, reviewing 
assessments, and learning to use the platform. These records ranged from 34 (shortest time spent for developing a course) to 248 (highest time spent for developing a course) hours [3].

The other downside is the issue with costs of MOOCs delivery and production. The production and delivery of MOOCs within higher education is quite expensive. This could be due to several factors including the high number of people involved in the process of creating MOOCs and the high-quality videos desired for them. According to Hollands et al., [4], an estimation of costs for production and delivery of MOOCs in four universities (Large Midwestern University, American Museum of Natural History, University of Manitoba and Teachers College, Columbia University) ranged from $\$ 39000$ to \$325300, per MOOC.

The purpose of this paper is to critically explore the challenges that students face when studying by means of 'Hybrid MOOCs with Flipped Classrooms' within Higher Education in the Kingdom of Saudi Arabia.

\section{Literature Review}

Many researchers have been integrating and exploring Massive Open Online Courses (MOOCs) with Flipped Classrooms, terming them Hybrid or Blended MOOCs. This integration not only applies in higher education, but also within schools. The target of this integration is to understand the influence of using a new teaching method on students' academic achievement, motivation, attitudes, and challenges in higher education. Although there are many advantages for utilising Hybrid MOOCs in education such as course flexibility, added interaction with other students, and enhanced quality of technology used for education, there are many challenges that students face when they study on the MOOCs platform or in the Flipped classrooms as presented in the literature.

A significant challenge of using Hybrid MOOCs is related to students' activities in discussion forums. There are several studies confirming that students did not participate actively in the discussion forums. According to Caulfield, et al., [5] at Stanford University, $62 \%$ of students participated in the discussion forums for one session or less, while $15 \%$ of participants did not use the discussion forums at all. Moreover, Bruff et al. [6] argue that students preferred social interaction in person during the class time, as they preferred not to discuss with each other via the online community. Adding to this, Holotescu, et al., [7] state that students have bad experience from online instructions in the discussion forums. Learners were disappointed because they did not obtain direct feedback regarding their work from the online teachers in the MOOCs forums. However, Narrainen [8] does not agree with these findings. In her study, she found that all students found discussion forums an appropriate venue where teachers effectively interact with students, answering their questions.

Another challenge, as seen in the literature, is that online and face to face activities are often not well coordinated. Some teachers who integrated MOOCs in their classroom were searching the relevant online contents due to a lack of preparation and organisation. This content cannot accurately match the materials of the course in class, not least because such content is developed simultaneously in class. Students report that there were discrepancies between the classroom's materials and online MOOCs contents. Another study reiterates this point where students believed materials of the video lectures in the MOOCs were not in alignment with the subjects covered in the classroom [6].

In addition, students mentioned that the video lectures were not as motivating and interesting as face to face lectures [9]. This is an impediment for MOOCs as one of its major strengths is the interactive multimedia facilitating education. Griffiths et al., [3] confirm this in their study where students recounted that the value of practical in-class tasks were slightly higher than computer-generated resources offered online.

The time required for Hybrid learning poses an additional challenge for students as they must spend more time to study inside the class with their tutors and more time at home working alone, as compared to the traditional classes where students only attend the class at a specific time. Students who study in Blended learning need to manage their time to participate in both face to face classes and on the MOOCs platforms [8]. Combéfis et al., [10] emphasise, based on their experience, that when Blended learning is applied, teachers must take into account students' busy schedules, the fact that they may have many modules to study, courses to complete, projects to finish, family obligations, and of course, maintenance of a social and domestic life.

\section{Research Methodology and Design}

This research has adopted a mixed-methods approach, consisting of survey (quantitative approach) plus semi-structured interviews (qualitative approach). This approach offers a more comprehensive account of the topic under study compared to quantitative or qualitative approaches individually.

The study has been conducted through 14 weeks in Majmaah University, Saudi Arabia. The content of the 'Educational Technology and Communication Skills' module was determined based on the main reference book 'Educational Technology and Communication Skills' by Mamad Alqomaizy, third edition, 2016. This book consists of fourteen chapters which the researchers and faculty members have selected ten from. During the study, one chapter from the book 
was taught to students every week and the Rwag platform was used in order to upload course materials. One of the important considerations which was taken into account when Flipped Classrooms were used together with Hybrid MOOCs was the concept of 'Personalised Learning Strategies' shown in Figure 1 below. According to Wang et al. [11] and Liu, Wei and Gao [12], there are three stages to implementing Hybrid MOOCs with Flipped Classrooms. The three phases are: before classroom, in classroom, and after classroom. They were used in the study as the Figure 1 describes.

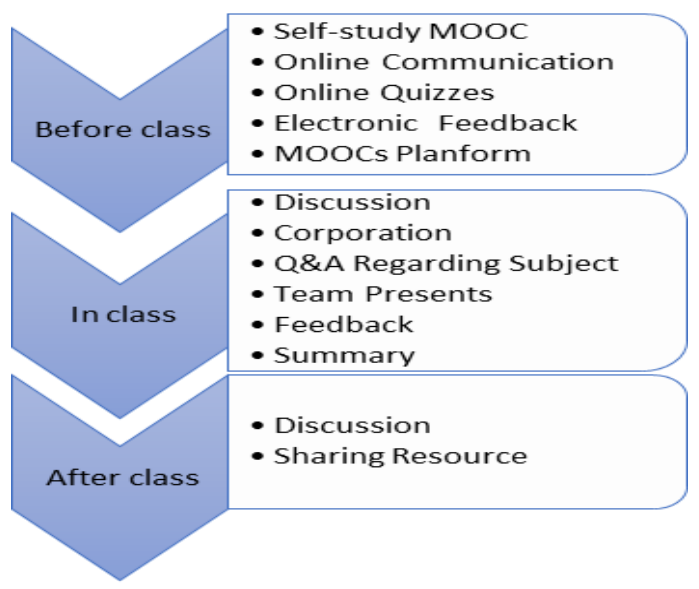

Figure 1: Stages to implementing Hybrid MOOCs with Flipped Classroom

\subsection{Study Sample Size}

As for the quantitative side of the study, the sample consisted of 45 students who participated in class for the duration of two hours per week. This was done from 12:00 to 14:00. A majority of participants came from 3 departments within Majmaah University: Islamic Studies, Arabic Language, and English Language. A noteworthy aspect of the study was that all participants were full-time undergraduates.

The qualitative aspect of the research comprised 8 students from the 45 mentioned. These 8 gave their consent to contribute to the interviews. The intention for having the interviews was to reach out more deeply on a personal level to students allowing them to express their challenges freely when they were undergoing 'Hybrid MOOCs with Flipped Classrooms', in a warm informal setting. The advantage of these interviews, therefore, would be to match the results with responses from the questionnaires in search of similarities or discrepancies.

\section{Results and Findings}

\subsection{Quantitative Results}

The questionnaires aimed to understand students' challenges when they were studying on the MOOCs platform with Flipped Classrooms. They consisted of 10 items and students were asked to tick boxes pertaining to the Likert scale regarding each item of enquiry.

The 5-point Likert scale was employed as follows: 1=Strongly Agree, 2=Agree, 3=Neutral, 4=Disagree, $5=$ Strongly Disagree. Accordingly, figures closer to 1 specify a higher agreement, whereas figures closer to 5 show lower agreement. Mean values from 2.5 to 3.5 designate moderate/medium agreement.

Table 1. Descriptive Analysis for students' challenges whilst learning through the MOOCs platform with Flipped Classrooms

\begin{tabular}{|c|c|c|c|c|}
\hline $\mathbf{N}$ & Statements & $\mathbf{N}$ & Mean & $\begin{array}{l}\text { Std. } \\
\text { Deviation }\end{array}$ \\
\hline 1 & $\begin{array}{l}\text { I didn't receive } \\
\text { helpful feedback } \\
\text { from my teacher }\end{array}$ & 45 & 4.24 & 0.857 \\
\hline 2 & $\begin{array}{l}\text { It has often been } \\
\text { hard to discover } \\
\text { what is expected of } \\
\text { me in this course }\end{array}$ & 45 & 4.13 & 0.726 \\
\hline 3 & $\begin{array}{l}\text { There is a lot of } \\
\text { pressure on me as a } \\
\text { student in this course }\end{array}$ & 45 & 4.16 & 0.767 \\
\hline 4 & $\begin{array}{l}\text { Sometimes I had } \\
\text { difficulty } \\
\text { allocating time to } \\
\text { participate in the } \\
\text { online component of } \\
\text { this course }\end{array}$ & 45 & 3.84 & 0.767 \\
\hline 5 & $\begin{array}{l}\text { Sometimes I } \\
\text { difficulty } \\
\text { allocating time to } \\
\text { participate in the } \\
\text { face to face } \\
\text { component of this } \\
\text { course }\end{array}$ & 45 & 3.98 & 0.753 \\
\hline 6 & $\begin{array}{lr}\text { I didn't } & \text { have } \\
\text { technical support } \\
\text { when I had problems }\end{array}$ & 45 & 4.20 & 0.757 \\
\hline 7 & $\begin{array}{l}\text { Slow internet } \\
\text { connectivity was an } \\
\text { issue for me }\end{array}$ & 45 & 3.62 & 0.960 \\
\hline 8 & $\begin{array}{l}\text { The materials for } \\
\text { online learning were } \\
\text { not well organised }\end{array}$ & 45 & 4.29 & 0.661 \\
\hline 9 & $\begin{array}{l}\text { The materials for } \\
\text { face to face learning } \\
\text { were not well } \\
\text { organised }\end{array}$ & 45 & 4.24 & 0.570 \\
\hline 10 & $\begin{array}{l}\text { Online and face to } \\
\text { face activities were } \\
\text { not well coordinated }\end{array}$ & 45 & 4.33 & 0.674 \\
\hline
\end{tabular}


As presented in Table 1, the mean of the 10 statements used to measure challenges ranged from 3.62 to 4.33 , which indicates overall low agreement to challenges in using Hybrid MOOCs with Flipped Classrooms. Among the 10 statements used, the statement, "Slow internet connectivity was an issue for me" (Mean=3.62, S. D=0.960) scored highest agreement, which reveals some challenges related to internet connectivity. This was followed by the statement, "Sometimes I had difficulty in allocating time to participate in the online component of this course" (Mean=3.84, S.D=0.767). On the other hand, the statement "Online \& face to face activities were not well coordinated" (Mean=4.33, S.D=0.674), scored low/medium agreement, indicating a good coordination between online and face to face activities.

\subsection{Qualitative Results}

The interviews posed two questions regarding student challenges that were faced when they were learning with Hybrid MOOCs with Flipped Classrooms.

\subsubsection{Challenges Facing Students when Using the} Online Component of MOOCs. Regarding difficulties, the interviews revealed that the obstacles were not preventative in terms of demotivating or deterring students from using the new teaching method in the long term.

Student 1 said, "At the beginning, I faced some difficulties, but later on, it gradually became easy for me to get online and study." Similarly, Student 2 stated, "I never found it difficult to use Hybrid MOOCs, with the only exception of slight difficulties in using the emails at the beginning. Other than that, everything was very clear and simple including videos, instructions, assessments, and tests", while Student 3 thought, "I sometimes experienced poor internet connection due to my location. In general, it became easy for me after that".

As explained earlier, such difficulties were overcome within a short period of time, as the Rwag support team and class teacher were the main advisers who gave instructions and removed barriers between students and the platform. Student 5 pointed to this support, "As a beginner, I had trouble registering on the platform but soon I asked the platform management and teacher to help me solve the problem. I really extend my gratitude to them for their prompt response and handling of the situation".

Similarly, student 6 mentioned, "Only in the first day I had difficulty. I was unable to log in but soon after contacting the platform management, they promptly reacted and solved the problem". It is known that several internet service providers are available in the area of Majmaah City. However, sometimes students experience poor internet connection when using the platform. This might be related to the signal strength of these companies which is something beyond university control. This is further explained by Student 3's comments, "Only at the beginning, I faced some difficulties logging in because it was my first time to study online and use electronic platforms. I sometimes experienced poor internet connection due to my location. In general, it became easy for me after that."

The results show no difficulties in using the online components of the platform due to clarity and simplicity, except in cases of students facing problems logging onto the platform for the first time, as well as acquainting themselves with the practice of online learning. In addition, emails, bad internet quality, and registration problems were irritating. However, the majority of students thought that such difficulty becomes less and less as they delve deeper into the course, especially with the help of platform technicians and managers who act quickly to assist in students' enquiries.

\subsubsection{Challenges Facing Students during Flipped} Classrooms. Students found that at the beginning, it was difficult for them to fit in the environment of the Flipped Classroom. The reason for this could be that the higher education teaching in Saudi Arabia depends almost entirely on traditional teaching methods which is face-to-face. Students in this teaching method are regarded as passive, which creates a gap between students and teachers, in addition to students with their peers. Moreover, there is no activity that allows students to connect with each other, except in the classroom discussions, which is carried out at a later stage of their educational progress. Furthermore, there is a lack of cooperative learning, with students working separately for their exams and assignments.

Student 1 remembered these issues, "I faced some problems such as getting to know my fellow classmates but after some time of sharing information with other students, watching videos, and cooperating with each other, the practice tends to become simple. We started helping each other through discussions and correcting mistakes"

Student 2 similarly noted, "The only normal difficulty at the beginning was to fit myself into a new classroom environment. However, it did not take long to adapt myself with the new situation."

Another reason why students faced difficulties in merging with each other was a psychological one. Students are shy, hesitant, and fearful of participating in the class as they do not know each other. Student 5 declared, "I had a problem the first week like the rest of the students. Everyone was shy, afraid, and embarrassed in front of the group. The main reason could be that all the students were in the first semester 
of university and didn't know each other. However, afterwards, the Flipped Classrooms went well."

In the same way, student 7 reaffirmed student 5 's considerations, "It took me some time to introduce myself to other friends and vice versa. Later, I become familiar with the practice".

The results showed that most students faced difficulties only in integrating with their classmates at the beginning. This is because it was the first time for them to use such teaching methods as students stated that they were not used to such educational experiences such as Flipped Classrooms.

\section{Discussion}

The responses from students obtained in the interviews and surveys regarding challenges faced by them when learning via Hybrid MOOCs were not significant and not necessarily related to the MOOCs themselves, but conditions surrounding their implementation.

The quantitative dimension of the study responds to this issue with students granting their observations exhibited in Table 1. It is shown that the mean of the 10 statements employed to rate challenges, stretched from 3.62 to 4.33 . This specifies a low agreement to challenges when working with Hybrid MOOCs. From the 10 sentences obtained, the one stating "Slow internet connectivity was an issue for me" (Mean=3.62, S. D=0.960) rated highest agreement, which discloses certain challenges caused by internet connection. After that, the sentence stating, "Sometimes I had difficulty in allocating time to participate in the online component of this course" (Mean=3.84, S. $\mathrm{D}=0.767$ ) came in afterwards. Contrarily, the statement "Online and face to face activities were not well coordinated" (Mean=4.33, $\mathrm{S} . \mathrm{D}=0.674$ ) had lowest agreement, with "The materials for online learning were not well organised" (Mean=4.29, S.D=0.661) and "I didn't receive helpful feedback from my teacher" (Mean=4.24, S.D=0.857) following after it respectively. Overall, we can judge that views towards challenges from students were relatively positive and serious challenges did not overwhelm them.

The qualitative section of this study generally supports the above-mentioned quantitative results as students only confronted challenges at the beginning only before they got used to Hybrid MOOCs. Some of their statements are as follows: Student 3 commented that "Only at the beginning, I faced some difficulties logging in because it was my first time to study online and use electronic platforms. He also remembered, "I sometimes experienced poor internet connection due to my location. In general, it became easy for me after that".

Scholarship focusing on challenges faced by learners when working with Hybrid MOOCs did not necessarily match the quantitative and qualitative outcomes of this study. Challenges existing for students, found in literature, include poor internet connection, non-alignment of online and face to face components of courses, lack of feedback, and language barriers.

Firstly, Adham's [13] study done in Saudi Arabia, resonated with the current research, finding that internet connection was a substantial challenge for students learning with MOOCs.

Secondly, Bruff et al.[6] and Bralić and Divjak [9] conducted studies on MOOCs in education where they saw that there were significant problems for students when the online component and face to face component were not aligned. This was contrary to this paper's findings where there was very good alignment in this regard according to students who answered the questionnaires.

Thirdly, results of the research by Holotescu et al. [7] and Liu et al. [14] indicated that feedback was a serious challenge for students as learners did not get direct feedback from the online instructor on the MOOCs. This is in contrary to the current study as the students indicated in the questionnaires that direct feedback at Majmaah University was very acceptable. However, another study by Al-Atabi and DeBoer [15] found that more than $\% 80$ of students considered the feedback received in their MOOCs course satisfactory, resonating with the current research.

Fourthly, there are a number of researchers who have mentioned language as a barrier since most MOOCs are in English [16, 17, 18, 19]. Gulatee and Nilsook [16] state that although MOOCs are very popular for users from various parts of the world, there still exists a barrier which does not allow everyone to enjoy this technology in their education. Being proficient in English is something that has not yet been seriously dealt with by MOOCs providers, especially for underdeveloped or developing countries who are thrilled to use MOOCs. Wu et al. [18] agree with this concern and declare,

"Massive Open Online Courses are becoming popular educational vehicles through which universities reach out to non-traditional audiences. Many enrolees hail from other countries and cultures, and struggle to cope with the English language in which these courses are invariably offered".

This, however, was not a barrier for students of Majmaah University who participated in the current research as the Hybrid MOOCs offered to them were in the local tongue (Arabic).

There are various theories describing effective technology use in education [21] which could be deliberated when contemplating challenges and barriers to effective MOOCs usage for education. However, for the current study, it would seem that the theory that grants a central role for teachers or seriously considers their position when technology is 
implemented, would be more appropriate due to the significant position the status of teacher has in Saudi culture. 'Diffusion of Innovations' [20] is a perspective that appraises the effective implementation of technology in social systems, while 'TPACK (Technological Pedagogical and Content Knowledge)' [22] focuses on types of information and awareness instructors are required to have in order to use technologies such as MOOCs in education, and 'SAMR (Substitution, Augmentation, Modification, and Redefinition)' [23] is a charter specialised in measuring the impact of technology implementation in educational tasks.

Diffusion of Innovation attempts to explain the processes influential in acceptance or rejection of the deployment of any innovation in the education curriculum, as social systems such as a group of students or a school can resist or be very open to this change. This theory investigates how a new technology can permeate through a population and emphasises on the lines of communication, opinion leaders, and gate keepers when this is done [21]. This theory also expounds that certain innovations might be better accepted than others when exposed to various groups. In the current study, students were very welcoming to new systems such as MOOCs which would mean that this innovative method would diffuse [21] in Majmaah University with ease, as far as learners are concerned.

TPACK concentrates on the role of personal characteristics on the integration of technologies in education. The disposition of the teacher is very important in this theory. The theory suggests teachers must be trained in three types of knowledge for effective technology integration into their classrooms: technological, pedagogical, and content knowledge [22]. It seems TPACK is very relevant for effective usage of MOOCs for Saudi Arabia as the transition between traditional teacher dominated classes to digital MOOCs education still needs the facilitation of teachers. Indeed, TPACK is quite applicable for the successful utilisation of Hybrid MOOCs in Majmaah University, due to the evolution from traditional teacher dominated conventional lectures to digital MOOCs, requiring the approval of teachers, their full cooperation, but also their competency.

SAMR is a theory attempting to assess the undertakings which integrate technology in education. The point this theory is trying to make is that there is a need to define and elaborate what constitutes an effective or successful form of learning for that particular technology. If there is a clear definition in the way a certain technology can be most effective, then that way of implementing it can be used for relevant disciplines [23]. For example, simulation software can be effective for game development but not necessarily for teaching history. Laboratory equipment is useful for teaching chemistry but not essentially for art. Documentaries are supportive for teaching history, but perhaps not very much for medicine. In this study, MOOCs are already being used in an appropriate manner in Majmaah University which is for education of undergraduate students. In addition, the Hybrid MOOC used are in Arabic language which adds to its suitable usage. MOOCs are beneficial for all subjects in Majmaah University, unless there are requirements of lab work or clinical tools needed.

As this study understands it, challenges to Hybrid MOOCs adoption in education can be reduced if certain known impediments are dealt with. Issues which cause irritation for students such as bad internet connection must be fixed. In addition, alignment must be seen between online and offline contents. It would be helpful if students get quick and complete feedback as well. Nevertheless, all these issues seem to be more related to how Hybrid MOOCs are implemented and maintained rather than a matter directly with the MOOCs themselves, since MOOCs themselves were very well accepted in the current context, i.e. at Majmaah University. The study showed that Hybrid MOOCs, as a new method, are accommodated well by participants of the study, but implementation strategies can be improved. The problems students mentioned, such as challenges in studying with Hybrid MOOCs, do not represent students' disavowal of Hybrid MOOCs as a method, but their concerns related to the fact that basic steps can make the implementation of this innovation more effective in their education which is a good sign. It appears that the theory of TPACK, emphasising teachers' understanding of the subject they are teaching, their general proficiency in pedagogy, and their adeptness with MOOCs, is very pertinent in facilitating the implementation processes of this educational technology. The technical staff of the education facility MOOCs is being implemented in can also help in improving internet speed. The students' answers in the questionnaires and interviews indicate that once they get acquainted with this new method, it becomes very easy. The teacher plays a critical role in how fast and easy students adapt to this new technology. The qualitative and quantitative findings of this study are good news for the long-term usage of Hybrid MOOCs in the Kingdom of Saudi Arabia as Majmaah is a main city and Majmaah University one of the main public institutions of higher education in the country.

\section{Conclusion}

This study is unique and first of its kind, to the authors' knowledge, in investigating the obstacles and challenges faced by students when Hybrid MOOCs with Flipped Classrooms are implemented within the higher education of Saudi Arabia. Mixed methods approach was employed in this research, consisting of interviews and questionnaires. When it comes to challenges related to MOOCs platform, it was found 
that poor connection was a major challenge for studying via MOOCs, which is not precisely related to MOOCs as an educational tool. Moreover, the interviews disclosed that there were social challenges at the initial stages of using Hybrid MOOCs with Flipped Classrooms, such as fear of participation, embarrassment, and shyness. This is understandable as the students just graduated from high school, this was their first semester in higher education, and it was the first time they had been exposed to this teaching method. The implications of the current research are broad since it reveals that the country is perhaps prepared for a transformation in its education system from the traditional to MOOCs, as are countries with similar educational contexts. This study can be a significant model for further studies done in the developing world as well.

\section{References}

[1] Karsenti, Thierry. "What the research says." International Journal of Technologies in Higher Education 10, no. 2 (2013): 23-37.

[2] Onah, Daniel FO, Jane Sinclair, and Russell Boyatt. "Dropout rates of massive open online courses: behavioural patterns." EDULEARN14 proceedings (2014): 5825-5834.

[3] Griffiths, Rebecca, Christine Mulhern, Richard Spies, and Matthew Chingos. "Adopting MOOCS on campus: A collaborative effort to test MOOCS on campuses of the university system of Maryland." Online Learning 19, no. 2 (2015): n2.

[4] Hollands, Fiona M., and Devayani Tirthali. "MOOCs: Expectations and Reality. Full report." Online Submission (2014).

[5] Caulfield, M., Collier, A., \& Halawa, S. "Rethinking online community in MOOCs used for blended learning" [Web log post]. Retrieved from https:// https://er.educause.edu/articles/2013/10/rethinking-onlinecommunity-in-moocs-used-for-blended-learning (Access date: 2013, October 6).

[6] Bruff, Derek O., Douglas H. Fisher, Kathryn E. McEwen, and Blaine E. Smith. "Wrapping a MOOC: Student perceptions of an experiment in blended learning." Journal of Online Learning and Teaching 9, no. 2 (2013): 187.

[7] Holotescu, Carmen, Gabriela Grosseck, Vladimir CREȚU, and Antoanela Naaji. "INTEGRATING MOOCs IN BLENDED COURSES." Elearning \& Software for Education 1 (2014).

[8] Narrainen, Gundeea. "When the Massive Open Online Courses, MOOC, become Hybrid at the Open University of Mauritius." In 4th International Conference on Higher Education Advances (HEAD'18), pp. 717-724. Editorial Universitat Politècnica de València, 2018.
[9] Bralić, Antonia, and Blaženka Divjak. "Integrating MOOCs in traditionally taught courses: achieving learning outcomes with blended learning." International Journal of Educational Technology in Higher Education 15, no. 1 (2018): 2

[10] Combéfis, Sébastien, Adrien Bibal, and Peter Van Roy. "Recasting a Traditional Course into a MOOC by Means of a SPOC." Proceedings of the European MOOCs Stakeholders Summit (2014): 205-208.

[11] Wang, Xin-Hong, Jing-Ping Wang, Fu-Ji Wen, Jun Wang, and Jian-Qing Tao. "Exploration and Practice of Blended Teaching Model Based Flipped Classroom and SPOC in Higher University." Journal of Education and Practice 7, no. 10 (2016): 99-104.

[12] Liu, Zhongwen, Li Wei, and Xia Gao. "A study on selfregulated micro-course learning and implicitly layered flipped classroom." Theory and Practice in Language Studies 6, no. 4 (2016): 870-877.

[13] Adham, Raniah Samir. "The use of Avatars in gendersegregated blended learning and MOOCs in Saudi Arabia." PhD diss., University of Reading, 2017.

[14] Liu, Xinghong, Junxiang Zhang, and Lin Zhang. "Application of MOOC in the Design of Hybrid Learning Strategies." In 2015 International Symposium on Educational Technology (ISET), pp. 129-133. IEEE, 2015.

[15] Al-Atabi, Mushtak, and Jennifer DeBoer. "Teaching entrepreneurship using massive open online course (MOOC)." Technovation 34, no. 4 (2014): 261-264.

[16] Gulatee, Yuwanuch, and Prachyanun Nilsook. "MOOC's Barriers and Enables." International Journal of Information and Education Technology 6, no. 10 (2016): 826-830.

[17] Fini, Antonio. "The technological dimension of a massive open online course: The case of the CCK08 course tools." The International Review of Research in Open and Distributed Learning 10, no. 5 (2009).

[18] Wu, Shaoqun, Alannah Fitzgerald, and Ian H. Witten. "Second language learning in the context of MOOCs." In CSEDU 2014, vol. 1, pp. 354-359. SCITEPRESS, 2014

[19] Engle, Deborah, Chris Mankoff, and Jennifer Carbrey. "Coursera's introductory human physiology course: Factors that characterize successful completion of a MOOC." The International Review of Research in Open and Distributed Learning 16, no. 2 (2015).

[20] Phillips, M. (2015) 'Digital technology integration', in Henderson, M. and Geoff, R. (eds.) Teaching and Digital Technologies: Big Issues and Critical Question Australia: Cambridge University Press.

[21] Rogers, E. M. "Diffusion of Innovations, 5th edn. Simon \& Shuster." Inc., New York (2003).

[22] Mishra, Punya, and Matthew J. Koehler. "Technological pedagogical content knowledge: A 
Journal of Information Technologies and Lifelong Learning (JITLL), Volume 2, Issue 1, June 2019

framework for teacher knowledge." Teachers college record 108, no. 6 (2006): 1017-1054.

[23] Jude, Lubega T., Mugisha Annet Kajura, and Muyinda Paul Birevu. "Adoption of the SAMR model to asses ICT pedagogical adoption: A case of Makerere University." International Journal of e-Education, $e$ Business, e-Management and e-Learning 4, no. 2 (2014): 106. 